\title{
Recovery of photoinactivated photosystem II in leaves: retardation due to restricted mobility of photosystem II in the thylakoid membrane
}

Riichi Oguchi · Husen Jia $\cdot$ James Barber · Wah Soon Chow

Published online: 4 November 2008

(C) Springer Science+Business Media B.V. 2008

Erratum to: Photosynth Res

DOI 10.1007/s11120-008-9363-5

The $x$-axis labels in Fig. 5a and $\mathrm{b}$ in the original publication should not be 'Time (min)' but should be 'Time (ms)'.

The online version of the original article can be found under doi: $10.1007 / \mathrm{s} 11120-008-9363-5$.

R. Oguchi · H. Jia · W. S. Chow ( $)$

Research School of Biological Sciences, The Australian National

University, Canberra ACT 0200, Australia

e-mail: chow@rsbs.anu.edu.au

R. Oguchi

Plant Sciences, Department of Biological Sciences, Graduate

School of Science, The University of Tokyo, 7-3-1 Hongo,

Bunkyo-ku, Tokyo, Japan

J. Barber

Division of Molecular Biosciences, Faculty of Science, Imperial

College London, London SW7 2AZ, UK 